ORIGINAL ARTICLE

\title{
Relation between physical exertion and heart rate variability characteristics in professional cyclists during the Tour of Spain
}

\author{
C P Earnest, R Jurca, T S Church, J L Chicharro, J Hoyos, A Lucia
}

Br J Sports Med 2004;38:568-575. doi: 10.1136/bjsm.2003.005140

Background: Continued exposure to prolonged periods of intense exercise may unfavourably alter neuroendocrine, neuromuscular, and cardiovascular function.

Objective: To examine the relation between quantifiable levels of exertion (TRIMPS) and resting heart rate $(\mathrm{HR})$ and resting supine heart rate variability (HRV) in professional cyclists during a three week stage race. Method: Eight professional male cyclists (mean (SEM) age 27 (1) years, body mass $65.5(2.3) \mathrm{kg}$, and maximum rate of oxygen consumption ( $\left(\mathrm{NO}_{2} \mathrm{MAX}\right) 75.6(2.2) \mathrm{ml} / \mathrm{kg} / \mathrm{min}$ ) riding in the 2001 Vuelta a España were examined for resting HR and HRV on the mornings of day 0 (baseline), day 10 (first rest day), and day 17 (second rest day). The rest days followed stages 1-9 and 10-15 respectively. HR was recorded during each race stage, and total HR time was categorised into a modified, three phase TRIMPS schema. These phases were based on standardised physiological laboratory values obtained during previous $\dot{V}_{2}$ MAX testing, where $\mathrm{HR}$ time in each phase (phase I = light intensity and less than ventilatory threshold (VT; $\sim 70 \% \mathrm{VO}_{2} \mathrm{MAX}$ ); phase II = moderate intensity between $\mathrm{VT}$ and respiratory compensation point (RCP; $\sim 90 \% \mathrm{~V}_{2}$ MAX); phase III = high intensity (>RCP)) was multiplied by exertional factors of 1, 2, and 3 respectively.

Results: Multivariate analysis of variance showed that total TRIMPS for race stages 1-9 (2466 (90)) were

See end of article for authors' affiliations

......................

Correspondence to: Dr Earnest, The Cooper Institute Center for Human Performance and Nutrition Research, 12330 Preston Road, Dallas, TX 75244, USA; cearnest@ cooperinst.org

Accepted 20 May 2003 greater than for stages 10-15 (2055 (65)) ( $<<0.0002)$. However, TRIMPS/day were less for stages 1-9 $(274(10))$ than for stages 10-15 (343 (11)) $(\mathrm{p}<0.01)$. Despite a trend to decline, no difference in supine resting HR was found between day 0 (53.2 (1.8) beats/min), day 10 (49.0 (2.8) beats/min), and day 17 (48.0 (2.6) beats $/ \mathrm{min})(p=0.21)$. Whereas no significant group mean changes in HR or HRV indices were noted during the course of the race, significant inverse Pearson product-moment correlations were observed between all HRV indices relative to total TRIMPS and TRIMPS/day accumulated in race stages 10-15. Total TRIMPS correlated with square root of mean squared differences of successive RR intervals $(r=-0.93 ; p<0.001)$, standard deviation of the RR intervals $(r=-0.94 ; p<0.001)$, log normalised total power $(r=-0.97 ; p<0.001)$, log normalised low frequency power $(r=-0.79 ; p<0.02)$, and $\log$ normalised high frequency power $(r=-0.94 ; \mathrm{p}<0.001)$.

Conclusion: HRV may be strongly affected by chronic exposure to heavy exertion. Training volume and intensity are necessary to delineate the degree of these alterations.

M any changes in physiological variables occur with chronic exposure to intense training loads. When these training loads become excessive, a broad class of terms is used to describe the attenuation in subsequent training and performance response. The most common are overexertion, overreaching, and overtraining, all of which typically involve unfavourable cardiovascular, neuromuscular, and/or hormonal alterations. ${ }^{12}$ To overcome the need for continual invasive measurements, exercise physiologists, coaches, and athletes often use resting heart rate (HR) to monitor fatigue and recovery relative to repeated training stimuli. ${ }^{1}$ However, the data on resting HR are equivocal, showing lower, normal, and faster resting HR in athletes suffering from these maladies. ${ }^{3}{ }^{4}$ The reason for this disparity is not completely understood. Some theories suggest that these responses are due to exhaustion of the neuroendocrine system or a decrease in catecholamine sensitivity. ${ }^{3-6}$ Several studies suggest that alterations in autonomic balance that accompany strenuous exercise can be examined non-invasively by assessing heart rate variability (HRV). ${ }^{7-13}$ Overtraining induced by heavy training increases cardiac sympathetic modulation during supine rest and attenuates baroreflex mediated response during an orthostatic man- oeuvre. ${ }^{12}{ }^{14}$ Conversely, optimal exercise training increases cardiac vagal activity in relation to sympathetic activity. ${ }^{15} 16$

HRV is a function of the synergistic action between the two branches of the autonomic nervous system, which act in balance through neural, mechanical, humoral, and other physiological mechanisms to maintain cardiovascular variables in an optimal range during changing external or internal conditions. Disease, emotional stress, and physical stress can all influence autonomic balance. Recent reports also show that HRV is inversely related to all-cause and cardiovascular disease mortality ${ }^{17}{ }^{18}$ Thus, the examination of HRV relative to parasympathetic activity alone or in combination with sympathetic nervous activity may provide a functional, non-invasive assessment of cumulative exertion and related fatigue.

A topic not fully examined in the literature related to chronic physiological stress is relative training volume and intensity. We theorise that a technique that may help in the examination of chronic exertion and HRV is to account for

Abbreviations: $H R$, heart rate; $H R V$, heart rate variability; $R C P$, respiratory compensation point; TRIMPS, training impulse; $\mathrm{VO}_{2} M A X$, maximum rate of oxygen consumption; VT, ventilatory threshold 
exercise training volume and intensity by using the TRIMPS concept initially proposed by Banister and Calvert ${ }^{19}$ and modified by Foster et $a l^{20}$ where TRIMPS stands for training impulse. In this paper, we examine the HRV response of professional road cyclists competing in a three week stage race known as the Vuelta a España, the third of the three annual classic stage races after the Giro d'Italia (April) and Tour de France (July). This type of race typically lasts 2122 days, entails 70-90 hours of competition, and covers $3000-3500 \mathrm{~km}$ with only two days of rest. Despite the long duration of the daily stages (four to five hours and 150$200 \mathrm{~km}$ ), exercise intensity is often high during the more physically taxing events, such as riding over high mountain passes, time trials, sprints, and "breakaways". ${ }^{21}$ On the basis of a report suggesting that the basal activity of the pineal gland, adrenal glands, and testis is decreased after such an event, ${ }^{6}$ we believe that the nature of this race lends itself to the examination of HRV during chronic exposure to prolonged heavy exertion.

\section{METHODS}

We recruited eight male cyclists from one of the world's leading professional cycling teams. All were highly competitive in the professional category. Several finished within the top 10 of the Giro d'Italia, Vuelta a España, or Tour de France between 1995 and 2002. Their age (mean (SEM) 27 (1) years), height (179 (1) cm), body mass $(65.5(2.3) \mathrm{kg})$, and percentage body fat $(8.3(0.1) \%)$ were assessed earlier in the season and before the race. Body fat was estimated using a skinfold method described elsewhere. ${ }^{6}$ Maximum rate of oxygen consumption $\left(\dot{\mathrm{V}}_{2} \mathrm{MAX}\right)$ for each rider was assessed four to five weeks before the race. All the subjects were in good health without arrhythmic events, as established by a normal physical examination including electrocardiograph and echocardiograph evaluation during the preceding year. All had normal endocrine and metabolic functions and no family history of diabetes mellitus. Written, informed consent was obtained from each subject in accordance with the regulations of the Universidad Complutense, Madrid, Spain.

\section{Characteristics of the 2001 Vuelta a España}

The Vuelta a España begins in late August/early September on the Spanish Mediterranean coast. In 2001, it included 21 daily race stages, with two days of rest (day 10 and day 17) (table 1). During this three week period, a total of $2989 \mathrm{~km}$ were covered and the total time raced for the overall winner was $\approx 71$ hours. The average total speed for this event was $42.5 \mathrm{~km} / \mathrm{h}$. The mean (SEM) daily distance covered per stage was 143 (13) $\mathrm{km}$ at altitudes ranging from sea level through to $2000 \mathrm{~m}$ above sea level. Most daily stages started at about 1330 hours and finished between 1700 and 1730 hours. Temperature ranged from $17^{\circ} \mathrm{C}$ to $30^{\circ} \mathrm{C}$. Nutrition, hydration, timing of food intake, and sleep were kept constant throughout the entire three week period. This is normal practice in cycling competitions to maintain circadian rhythms and consistency among riders. ${ }^{22}$ Mean daily food intake during this type of competition is about $840 \mathrm{~g}$ carbohydrate, $200 \mathrm{~g}$ protein, and $158 \mathrm{~g}$ fat corresponding to about $23.5 \mathrm{MJ}^{22}$

\section{Laboratory exercise testing and race monitoring}

During the four to five weeks before the race, all subjects performed an incremental exercise test to determine reference HRs corresponding to the ventilatory threshold (VT) and the respiratory compensation point (RCP). All tests were performed on a bicycle ergometer and followed a ramp protocol until exhaustion. Workload during these tests increased $25 \mathrm{~W} / \mathrm{min}$ until exhaustion. These methods have been described in detail elsewhere. ${ }^{21}$ HR was continuously recorded during the tests with a telemeter (Polar S710; Polar Electro, Oy, Finland). The workload corresponding to VT was determined using the criteria of an increase in both the ventilatory equivalent of oxygen $\left(\mathrm{VE} / \mathrm{VO}_{2}\right)$ and end tidal partial pressure of oxygen $\left(\mathrm{PETO}_{2}\right)$ with no concomitant increase in the ventilatory equivalent of carbon dioxide ( $\mathrm{VE} /$ $\left.\mathrm{V}_{\left(\mathrm{O}_{2}\right.}\right) .{ }^{23}$ The workload eliciting the RCP was determined using the criteria of an increase in both $\mathrm{VE} / \mathrm{VO}_{2}$ and $\mathrm{VE} / \mathrm{VCO}_{2}$ and a decrease in end tidal partial pressure of carbon dioxide $\left(\mathrm{PETCO}_{2}\right) .^{23}$

We also recorded HR for each rider during each stage of the race using the Polar S710 telemeter. All data recorded were analysed using a computer program (Polar Precision Performance 3.02; Polar Electro), which allows the user to select reference HR values relative to established levels of exercise intensity. To examine the exertional intensity/ volume relation for each rider during the race, we divided recorded HR values into three phases according to the reference values obtained during a previous ramp cycle ergometer test. These phases were: I (light intensity; <VT); II (moderate intensity; between VT and RCP); III (high intensity; > RCP).

To estimate the exertional volume and intensity for each rider, we adopted a modified approach proposed by Foster et $a l^{19}$ to the original TRIMPS concept published by Banister and Calvert. ${ }^{20}$ This modified TRIMPS model integrates total exercise participation time and relative HR based on the phases outlined above into an exercise volume/intensity measurement. This measurement is obtained by taking the rider's HR for the time spent in each phase and multiplying the accumulated time spent in this phase by a multiplier. Specifically, HR during phase I is scored as l, HR during phase II is scored as 2, and HR in phase III is given a score of 3:

Total TRIMPS $=(\min$ of phase I HR $\min \times 1)+($ min of phase II HR min $\times 2)+(\min$ of phase III HR $\min \times 3)$

\section{HRV analysis}

To assess HRV we collected baseline (day 0) RR intervals two days before the race and during the two allotted rest days after stages 1-9 (day 10) and stages 10-15 (day 17). We used these days because our data were obtained under field testing conditions in which rider time was at a premium relative to their competition schedule. We were unable to collect data on the last day of the event because this was not a rest day and riders were preparing for the final day of racing (table 1 ). We used an IBM compatible PC equipped with a program for signal processing and HRV analysis (Polar Precision Performance SW 3.02). A two channel electrocardiograph signal was detected by a Polar Heart Rate Monitor and transmitted online to a Polar S810 watch receiver. The computer program labelled each QRS complex, and the resulting signal was passed through a filter that eliminates ectopic beats and artifacts. In addition, an RR interval tachogram was displayed for manual editing, and areas of ectopy or artefact were identified and removed by manual deletion. Each edited RR interval was replaced with an average value. Segments containing more than $15 \%$ of edited $\mathrm{RR}$ intervals were interpreted as a premature beats and excluded from data analysis. These segments accounted for $<2 \%$ of edited 10 minute intervals in every subject. The filtering techniques are described in previous reports. ${ }^{24} 25$

Resting RR intervals were collected in the supine position for 15 minutes during baseline on day 10 and day 17. HRV was estimated from the last four minutes of data collection. Data were collected on subjects each test morning when they woke up in a semidarkened room. The stability and reliability of time and frequency domain measures of short term resting 


\begin{tabular}{|c|c|c|c|}
\hline Date & Stage & Distance $(\mathrm{km})$ & Terrain \\
\hline Sept 08 & $1 \mathrm{st}$ & 12 & Flat: individual time trial \\
\hline Sept 09 & 2nd & 147 & Flat \\
\hline Sept 10 & $3 r d$ & 141 & Flat \\
\hline Sept 11 & 4 th & 175 & Flat \\
\hline Sept 12 & 5 th & 161 & Mountain \\
\hline Sept 13 & 6 th & 181 & Flat \\
\hline Sept 14 & 7 th & 44 & Flat: individual time trial \\
\hline Sept 15 & 8 th & 195 & Mountain \\
\hline Sept 16 & 9th & 179 & Flat \\
\hline Sept 17 & $\begin{array}{l}\text { Rest day (easy training } \\
\text { of } \sim 70 \mathrm{~km} \text {; no stage; HRV } \\
\text { assessed in the morning) }\end{array}$ & & \\
\hline Sept 18 & 10th & 168 & Mountain \\
\hline Sept 19 & 11 th & 154 & Mountain \\
\hline Sept 20 & 12 th & 17 & Mountain: time trial \\
\hline Sept 21 & 13 th & 206 & Flat \\
\hline Sept 22 & 14 th & 171 & Flat \\
\hline Sept 23 & 15 th & 207 & Mountain \\
\hline Sept 24 & $\begin{array}{l}\text { Rest day (easy training } \\
\text { of } \sim 70 \mathrm{~km} \text {; no stage; HRV } \\
\text { assessed in the morning) }\end{array}$ & & \\
\hline Sept 25 & 16 th & 153 & Flat \\
\hline Sept 26 & 17 th & 159 & Flat \\
\hline Sept 27 & 18 th & 154 & Flat \\
\hline Sept 28 & 19 th & 168 & Flat \\
\hline Sept 29 & 20 th & 181 & Mountain stage \\
\hline Sept 30 & $21 \mathrm{st}$ & 38 & Flat time trial \\
\hline
\end{tabular}

HR and HRV assessed day to day for five consecutive days in healthy active men has been reported previously. The authors of these reports suggest that, when HRV is measured in early morning, after an overnight fast and before any strenuous activity, the measurements are highly reproducible (intraclass correlation coefficient $>0.97$ for all HR and HRV indices). ${ }^{26}$ This was the procedure followed in our study, HRV measurements on days 10 and 17 being performed in early morning after an overnight fast. Because we were operating under field conditions, all subjects breathed spontaneously. Frequency and time domain methods were used to calculate HRV.

\section{Time domain analysis}

To assess the time domain measures, we analysed the standard deviation of all RR intervals ( SDNN) over the given measurement period and the square root of the mean of the sum of the squares of differences between adjacent RR intervals (rMSSD). SDNN reflects the parasympathetic and sympathetic influence, and rMSSD is considered to be an index of parasympathetic modulation of HR. ${ }^{27}$

\section{Frequency domain analysis}

We used an autoregressive model to estimate the power spectrum densities for the frequency domain. The power spectra were quantified by measuring the area in three frequency bands. We reported the high frequency power $\left(\mathrm{P}_{\mathrm{HF}} ; 0.15-0.40 \mathrm{~Hz}\right.$; measures the beat to beat variability and appears to be mediated by variations in parasympathetic activity), low frequency power $\left(\mathrm{P}_{\mathrm{LF}} ; 0.04-0.15 \mathrm{~Hz}\right.$; thought to reflect both vagal and sympathetic activities), and total frequency power $\left(\mathrm{P}_{\mathrm{T}} ; 0.04-0.40 \mathrm{~Hz}\right.$; represents overall variability). ${ }^{27}$

\section{Statistical analysis}

We began our analysis using a repeated measures multivariate analysis of variance to determine overall statistical effects for HR and HRV indices. If a significant statistical result was noted, a Fisher's least significant difference, post hoc analysis was undertaken. TRIMPS data were examined for absolute values, as well as for relative contributions-that is, TRIMPS/day. To normalise their distribution, we applied a natural logarithmic transformation $(\mathrm{ln})$ to all HRV variables analysed in the frequency domain $\left(\mathrm{P}_{\mathrm{HF}}, \mathrm{P}_{\mathrm{LF}}, \mathrm{P}_{\mathrm{T}}\right)$. We used a Pearson product-moment correlation analysis to examine the relation between the exercise volume and intensity-that is, TRIMPS—and resting HR and HRV.

\section{RESULTS}

The mean (SEM) physiological characteristics of the riders in this study included a $\dot{\mathrm{VO}}_{2} \mathrm{MAX}$ of 75.6 (2.2) $\mathrm{ml} / \mathrm{kg} / \mathrm{min}$, maximal power output of 498 (14) W, and HRMAx of 191 (1) beats/min. Average VT occurred at a power output of 325 (13) W (78.9 (2.5)\% of $\left.\dot{\mathrm{V}}_{2} \mathrm{MAX}\right)$ and a HR of 152 (3) beats/ min (79.6 (1.5)\% HRMAX). Average RCP occurred at a power output of 438 (12) W (91.3 (1.4)\% of $\left.\dot{\mathrm{V}}_{2} \mathrm{MAX}\right)$ and a HR of 176 (3) beats/min (90.5 (1.1)\% HRMAX).

Overall, our repeated measures multivariate analysis of variance showed significant effects for TRIMPS and all resting HR and HRV variables $(p<0.001)$. Only the TRIMPS data showed significant post hoc effects after an analysis of group means. However, significant correlations were found for all HRV indices accumulated in stages 10-15. Details of these findings are outlined below.

\section{Trimps}

Stages 1-9 of racing were characterised by $1235 \mathrm{~km}$ of riding inclusive of two days of time trials $(56 \mathrm{~km})$, five days of flat, mass start stage racing $(823 \mathrm{~km})$, and two days of mountain stages $(356 \mathrm{~km})$. Total TRIMPS experienced for riders during this period was 2466 (90) (274 (10) TRIMPS/day; table 2). Day 10 was a rest day. Stages 10-15 were characterised by $923 \mathrm{~km}$ of riding inclusive of one up hill or mountain time trial $(17 \mathrm{~km})$, two days of flat, mass start stage racing $(377 \mathrm{~km})$, and three days of mountain stages $(529 \mathrm{~km})$. Total TRIMPS experienced for riders during this time period was 2055 (65) (343 (11) TRIMPS/day).

Comparisons of total TRIMPS showed that even though overall TRIMPS for stages 1-9 were greater than for stages $10-15(\mathrm{p}<0.0002)$, average TRIMPS/day was greater during 


\begin{tabular}{|c|c|c|c|c|}
\hline & \multicolumn{4}{|l|}{ TRIMPS } \\
\hline & Phase I & Phase II & Phase III & Total \\
\hline \multicolumn{5}{|l|}{ Absolute TRIMPS } \\
\hline Stages $1-9$ & $1196.63(49.54)$ & 861.00 (127.04) & $408.75(65.86)$ & $2466.38(90.37)$ \\
\hline Stages $10-15$ & 950.25 (73.39) & 892.50 (87.32) & $212.63(23.51)$ & $2055.38(64.78)$ \\
\hline$p$ Value & $<0.007$ & 0.71 & $\begin{array}{l}<0.0005 \\
\text { l }\end{array}$ & $<0.0002$ \\
\hline \multicolumn{5}{|l|}{ TRIMPS/day } \\
\hline Stages $1-9$ & $133.00(5.49)$ & $95.63(14.14)$ & $45.50(7.31)$ & $274.13(10.04)$ \\
\hline Stages $10-15$ & $158.50(10.79)$ & $148.75(14.54)$ & $35.50(12.96)$ & $342.75(10.84)$ \\
\hline p Value & $<0.02$ & $<0.001$ & 0.20 & $<0.01$ \\
\hline
\end{tabular}

stages $10-15(p<0.01)$. Specific phase comparisons showed a greater accumulation of TRIMPS for phase I $(p<0.007)$ and phase III $(p<0.0005)$. However, no differences were noted for phase II absolute TRIMPS. When expressed as TRIMPS/day, in phase I $(\mathrm{p}<0.02)$ and phase II $(\mathrm{p}<0.001)$ they were greater for stages $10-15$ than for stages $1-9$, despite four fewer days of racing during the latter time period.

\section{HRV analysis}

Post hoc analysis examining group mean HRV comparisons showed no significant statistical effect between baseline (day 0 ), day 10, and/or day 17 (table 3). Furthermore, no significant correlation was observed between TRIMPS or TRIMPS/day accumulated during stages 1-9 and either time domain HRV indices (fig 1A, C) or frequency domain HRV indices (fig 2A-F). However, a significant inverse correlation was observed for total TRIMPS accumulated in stages 10-15 and each HRV component: $\operatorname{rMSSD}(r=-0.93 ; \mathrm{p}<0.001$; fig 1B), SDNN ( $r=-0.94 ; \mathrm{p}<0.001$; fig $1 \mathrm{D}), \operatorname{lnP}_{\mathrm{LF}}(r=$ $-0.79 ; \mathrm{p}<0.02$; fig $2 \mathrm{~B}), \ln \mathrm{P}_{\mathrm{HF}}(r=-0.94 ; \mathrm{p}<0.001$; fig $2 \mathrm{D})$, and $\ln \mathrm{P}_{\mathrm{T}}(r=-0.97 ; \mathrm{p}<0.001$; fig $2 \mathrm{~F})$. The same results were observed when we expressed the data as TRIMPS/day for each HRV index (data not presented).

\section{DISCUSSION}

The principal finding from this trial is the observation that changes in supine resting HRV are inversely related to exercise volume and intensity. Although several other groups have examined the relation between "overtraining" and $\mathrm{HRV},{ }^{8-13}$ this is the first paper to examine the relation between HRV and chronic exposure to heavy exercise after adjustment for the training volume/intensity relation. Although we did not examine overtraining/overreaching per se, we believe that adjusting for the volume/intensity relation is important for future studies investigating the relation between HRV and periods of heavy physical exercise for the following reasons. Firstly, athletic training and competition are stochastic and prone to changing intraindividual responses to an imposed exercise challenge. Inherent within this paradigm is the idea that adaptation is, in and of itself, allostatic and dependent on a variety of mechanisms including psychosocial, neuroendocrine, musculoskeletal, and cardiovascular responses. A fundamental difficulty in using HRV to examine changes associated with chronic bouts of heavy physical exertion is accounting for individual responses to and from a training stimulus.

For example, during each one of the professional three week stage races (Giro d'Italia, Tour de France, Vuelta a España), some riders are selected to try to win stage victories and are often protected by drafting techniques. This reduces physical exertion in an effort to "save" that cyclist for greater effort needed later in the race or overall competition in general. To accomplish this, other riders, known as domestiques, play a supportive role by blocking and working for the rider selected to attempt a stage win. Inevitably, these riders expend a greater amount of energy during competition and training (fig 3). Examining the group means in our study suggests a trend for various HRV indices to increase from baseline to day 10, and then generally be maintained through to day 17 of stage racing (table 3). Although not significant, all HRV indices tended to increase during the first 10 days of racing and remain higher than baseline through to day 17. However, the statistical error-that is, SEM-surrounding the mean of the data suggests that there is great intraindividual variability in HRV during race conditions, which will prevent differences in the mean group variables between time points reaching statistical significance. Therefore, quantifying physical exertion relative to training volume and intensity seems to be a more logical way of examining the relation between an athlete's response to exercise training and competition. To adequately examine the relation between HRV and physical exertion in the field, it is necessary to

Table 3 Supine heart rate and heart rate variability characteristics of eight professional cyclists during the 2001 Vuelta a España

\begin{tabular}{|c|c|c|c|}
\hline & Baseline & Day 10 & Day 17 \\
\hline Heart rate (beats/min) & $53.23(1.8)$ & $48.99(2.8)$ & $48.02(2.6)$ \\
\hline \multicolumn{4}{|l|}{ Time domain measures } \\
\hline SDNN (ms) & $59.10(6.52)$ & $70.44(5.08)$ & $60.67(6.65)$ \\
\hline RMSSD (ms) & 44.89 (5.21) & $51.98(5.52)$ & $49.54(7.43)$ \\
\hline \multicolumn{4}{|c|}{ Frequency domain measures } \\
\hline $\operatorname{Ln} P_{L F}\left(\mathrm{~ms}^{2}\right)$ & $6.83(0.25)$ & $7.22(0.15)$ & $6.95(0.28)$ \\
\hline $\operatorname{LnP}_{\mathrm{HF}}\left(\mathrm{ms}^{2}\right)$ & $6.28(0.25)$ & $6.34(0.26)$ & $6.26(0.39)$ \\
\hline $\operatorname{LnP}_{\mathrm{T}}\left(\mathrm{ms}^{2}\right)$ & $7.35(0.20)$ & $7.61(0.15)$ & $7.44(0.30)$ \\
\hline \multicolumn{4}{|c|}{$\begin{array}{l}\text { Data are mean (SEM). } \\
\text { rMSSD, Root mean square successive difference of RR intervals; SDNN, standard deviation of RR intervals; } \ln P_{H F} \text {, } \\
\text { log high frequency spectral power }(0.15-0.40 \mathrm{~Hz}) ; \ln \mathrm{P}_{\mathrm{LF}} \text {, log low frequency spectral power }(0.04-0.15 \mathrm{~Hz}) ; \ln \mathrm{P}_{\mathrm{T}} \text {, } \\
\text { log total frequency spectral power }(0.04-0.40 \mathrm{~Hz}) \text {. }\end{array}$} \\
\hline
\end{tabular}



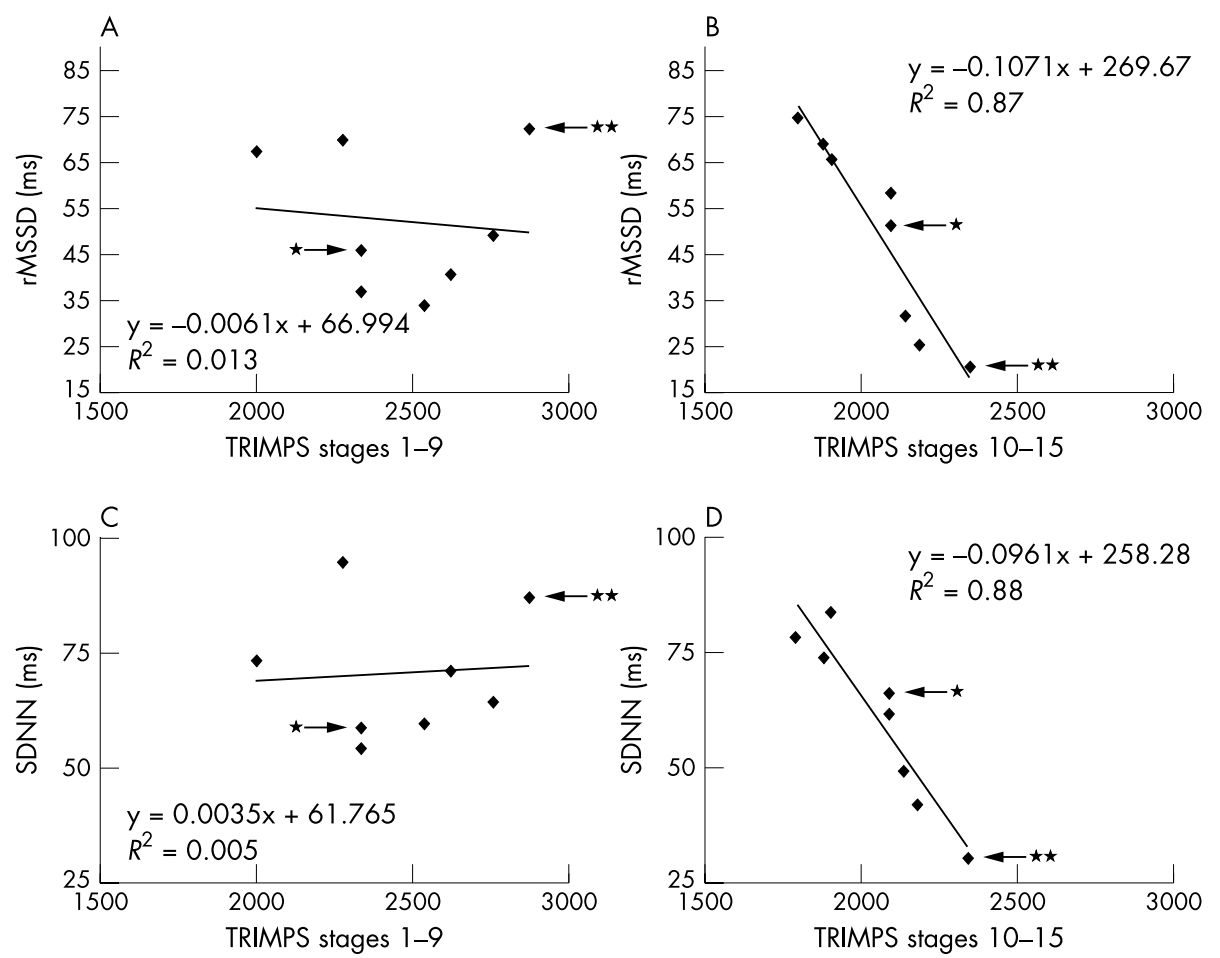

Figure 1 Time domain analysis of eight professional cyclists participating in the 2001 Vuelta a España. (A, B) Square root of the mean of the sum of the squares of differences between adjacent RR intervals (rMSSD). (C, D) Standard deviation of all RR intervals (SDNN). (A, C) TRIMPS accumulated for stages 1-9. (B, D) TRIMPS accumulated for stages 10-15. The heart rate variability response of a multistage winner/team leader (*) and a domestique $\left({ }^{*}\right)$ are indicated. These are the individual cyclists analysed in fig 3.

account for the relative degree of physical effort expended by each rider. We illustrate this in our present study using a modified TRIMPS concept.

From these results, there seems to be little correlation between HRV and exercise volume during stages 1-9. However, strong inverse correlations are observed between HRV and exercise volume and intensity in stages 10-15. One of the most distinguishing features between these two periods is the average TRIMPS/day accumulated by the riders. Even though each rider rode a greater distance and accumulated more TRIMPS in stages 1-9 than in stages 1015, it is notable that more TRIMPS/day were accumulated during the second time period. Overall, however, we suggest that the HRV alterations observed are due to the cumulative physical effort over all 15 stages of racing. This pattern is observed by examining the HRV response of a team leader and domestique in figs 1 and 2: a decrease in HRV is observed for the domestique after 15 stages of racing, whereas there is little change in the HRV values of the team leader. Unfortunately, there are no similar trials with which to compare our results. The closest may be those reports examining HRV, exercise, and/or "overtraining."

For example, Uusitalo et $a^{28}$ examined changes in baroreflex sensitivity, plasma volume, and resting HR and blood pressure variability induced by heavy training in female endurance athletes. During this trial, nine athletes increased their training intensity and volume component by $100-130 \%$ for six to nine weeks. In five overtrained athletes, defined as having a decrease in $\dot{\mathrm{V}}_{2} \mathrm{MAX}, \mathrm{P}_{\mathrm{LF}}$ increased during supine rest. The same group, using a similar trial design, later confirmed the results of this trial. ${ }^{12}$ Again, five subjects were defined as being overtrained, showing a decrease in $\dot{\mathrm{V}}_{2} \mathrm{MAX}$, and an increase in low frequency spectral power $\mathrm{P}_{\mathrm{LF}}$ during supine rest. Changes in total spectral power $\mathrm{P}_{\mathrm{T}}$ during standing correlated positively with changes in $\dot{\mathrm{V}}_{2} \mathrm{MAX}$. The authors concluded that heavy training can increase cardiac sympathetic modulation during supine rest and attenuated biphasic baroreflex mediated response appearing just after shifting to an upright position.

In contrast, Hedelin et al ${ }^{29}$ reported HRV findings in nine elite canoeists involved in a six day training camp consisting of cross country skiing and strength training totalling about 13 hours, which corresponded to a $50 \%$ increase in the athletes' training load. During this short period of vigorous training, time to exhaustion, $\dot{\mathrm{V}} \mathrm{O}_{2} \mathrm{MAX}$, and maximal lactate decreased. However, no group changes in HRV were found at rest or after a tilt test. Although resting HR did decrease, this was attributed to an increase in plasma volume. The authors concluded that HRV did not seem to be affected by short term "overtraining." In a case study presented by the same group, however, increased high frequency and total powers $\left(\mathrm{P}_{\mathrm{HF}}\right.$ and $\mathrm{P}_{\mathrm{T}}$ ) in the supine position were observed in one athlete after a diagnosis of overtraining." Interestingly, the authors concluded that there is a shift toward increased HRV, particularly the high frequency range, together with a reduced resting HR. They further suggest that this causes a cardiac autonomic imbalance with extensive parasympathetic modulation when overtrained. Thus, some disagreement exists in the literature about HRV and overtraining. We hypothesise that true overtraining and heavy exertion would attenuate the HRV response for several reasons. Firstly, HR is intrinsically regulated by the balance between the sympathetic and parasympathetic nervous system. In brief, stimulation of the sympathetic nervous system increases HR through the release of adrenaline (epinephrine) and noradrenaline (norepinephrine), which accelerate depolarisation of the sinoatrial node. The same catecholamines also increase cardiac contractility. Parasympathetic activity is regulated by the release of acetylcholine, which acts on the vagus nerve to attenuate sinus discharge. Both of these factors can 

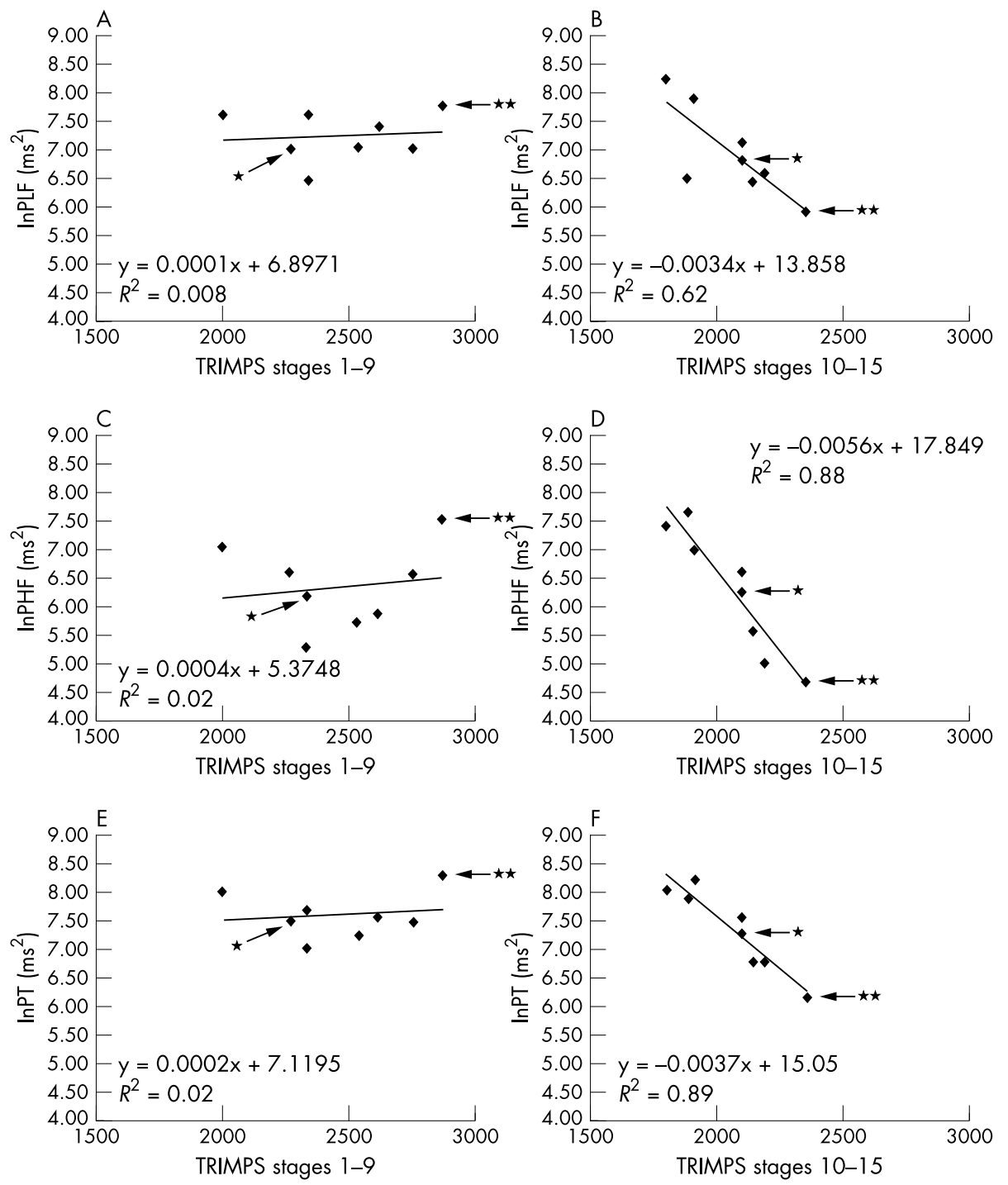

Figure 2 Frequency domain analysis of eight professional cyclists participating in the 2001 Vuelta a España. The power spectra were quantified by measuring the area in three frequency bands and are low frequency power $\left(P_{L F} ; 0.04-0.15 \mathrm{~Hz} ; A, B\right)$, high frequency power $\left(P_{H F} ; 0.15-0.40 \mathrm{~Hz} ; C\right.$, D), and total frequency power $\left(P_{\mathrm{T}} ; 0.04-0.40 \mathrm{~Hz} ; \mathrm{E}, \mathrm{F}\right)$. (A, C , E) TRIMPS accumulated for stages 1-9. (B, D E) TRIMPS accumulated for stages $10-15$. The heart rate variability response of a multistage winner/team leader $\left({ }^{*}\right)$ and a domestique $\left({ }^{* *}\right)$ are indicated. These are the individual cyclists analysed in fig 3 .

influence HRV and are referred to as autonomic balance. Optimal exercise conditioning, coupled with adequate recovery, creates a healthy "imbalance" per se between the activities of the sympathetic and parasympathetic nervous system in favour of greater vagal dominance. This is due to an increase in parasympathetic activity and possibly a decrease in sympathetic activity. ${ }^{30}{ }^{31}$ In addition, training may also decrease the intrinsic rate of firing of the sinoatrial node pacemaker tissue, ${ }^{32} 33$ which accounts for the bradycardia associated with highly conditioned athletes. ${ }^{32}{ }^{33}$ Thus, if excessive training were to alter the high frequency component of HRV - that is, parasympathetic tone-one would expect to see a decrease in the variable.

Secondly, and in support of this premise, overtraining syndromes are characterised by a decreased intrinsic sympathetic activity and sensitivity of target organs to catecholamines, as indicated by decreased catecholamine excretion, decreased $\beta$ adrenoceptor density, decreased $\beta$ adrenoceptor mediated responses, and increased resting plasma noradrenaline concentrations and responses to exercise. ${ }^{34}$ Earlier studies on athletes showed that changes in activity of the autonomic nervous system, as assessed by HRV during a dynamic orthostatic test, may detect signs of fatigue that may result in overtraining. An impaired baroreflex response after the tilt is such a marker. ${ }^{12}{ }^{14}$ Although we attempted to perform an "orthostatic test" by having the cyclists stand for six minutes after supine HRV data had been collected, the orthostatic test is typically performed using a tilt table. Our data are not shown because we feel that they are inconsistent and show great variability-that is, SD and SEM. We attribute this to several possibilities including accessory muscle movement while the athletes were maintaining their balance or "fidgeting." In addition, HRV in general has been shown to be greater in athletes than in those predisposed to cardiovascular events, ${ }_{17}^{18} 2226$ further suggesting that HRV would increase during a "state of health" or decrease during a state of disease or stress.

Using as an example the study of Hedelin et al, ${ }^{29}$ the athletes (canoeists) were probably not overtrained, but simply overreached. Moreover, although the training was intense, it only amounted to about two hours a day. Although strenuous and tiring, it may have been insufficient 

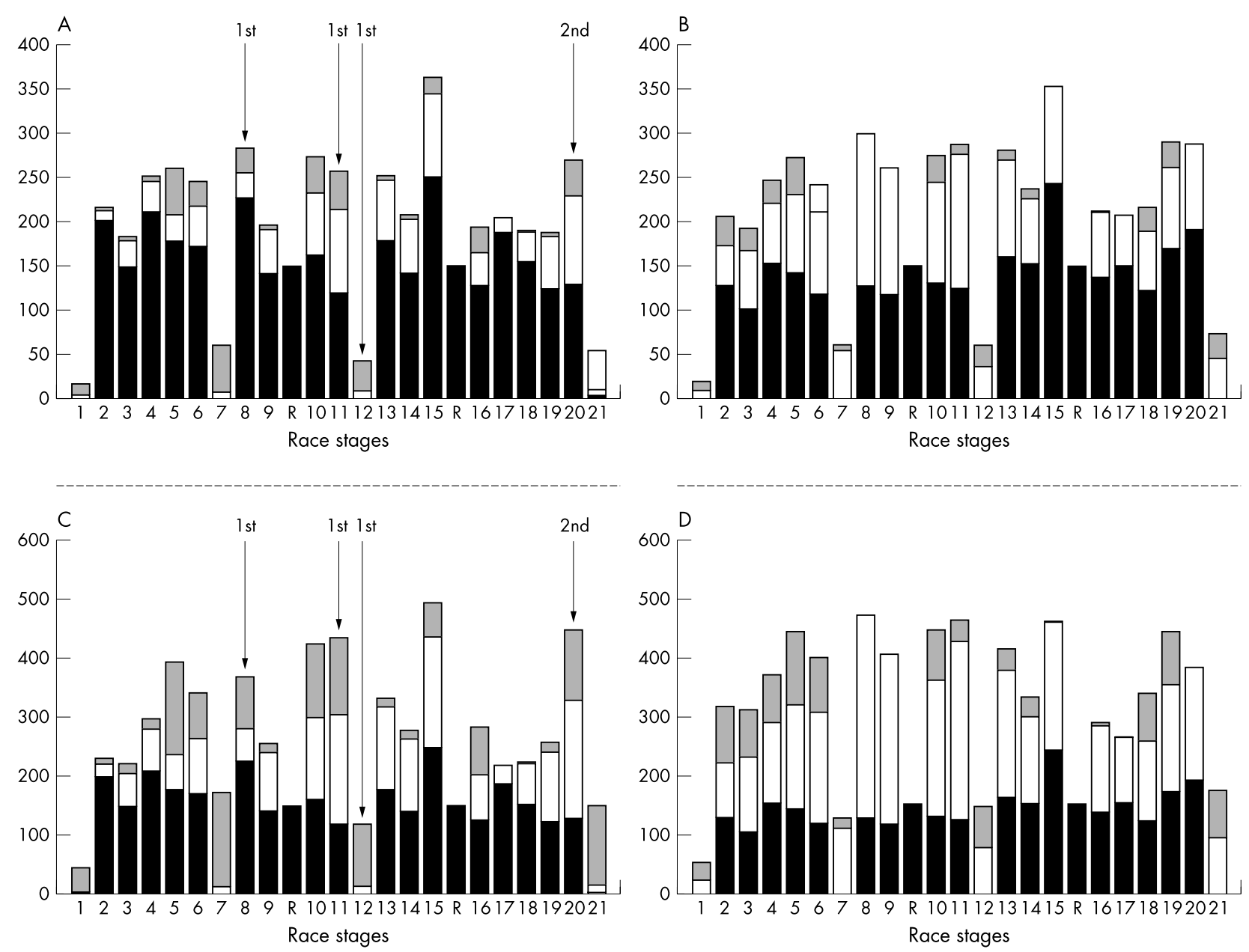

Figure 3 Individual time (minutes; A, B) and TRIMPS (C, D) accumulated during each individual race stage. (A, C) Data for a multiple stage winner who accumulated three stage wins and one second place finish. (B, D) Data for a domestique. Black represents phase I, white phase II, and grey phase III. The letter " $R$ " on the $x$ axis represents rest days, when riders performed light intensity recovery rides lasting about 120 minutes.

to elicit any change in autonomic balance in such a short period of time. This is supported by data in our study showing no changes in HRV after 10 days of competitive riding at about four to five hours a day. Support for our hypothesis comes from the study of Pichot et al ${ }^{13}$ who monitored the HRV of seven middle distance runners undertaking three weeks of heavy training, followed by a relatively restful week. The results showed a significant and progressive decrease in parasympathetic indices (by $41 \%$ ) during the three weeks of heavy training. This was followed by a $46 \%$ increase during the rest week. Conversely, indices of sympathetic activity followed the opposite trend. The most obvious explanation for the fact that we did not find HRV differences across the three measurement periods in our study is the individual variance in TRIMPS. Thus, the HRV comparison within the whole group is probably affected by individual volume and intensity of exercise expended during the race, which is supported by our observation that HRV correlated negatively with TRIMPS.

Another explanation for our findings relates to cardiac fatigue and alterations in the neuroendocrine axis, which is accompanied by a reduction in cardiac $\beta$ adrenergic responsiveness associated with exercise. ${ }^{35}$ One cause of these responses may be the sustained tachycardia of nearly 21 days of continuous professional racing. Left ventricular function has been shown clinically to be transiently decreased after supraventricular tachycardia(s) or rapid pacing. ${ }^{36-38}$ These types of change, in addition to a reduction in cardiac $\beta$ adrenergic responsiveness, have been noted after as little as one hour of exercise, ${ }^{35} 39$ as well as after the completion of an Ironman triathlon. ${ }^{40}$ The reduced responsiveness to catechols also correlates closely with the degree of cardiac fatigue, as measured by a reduction in ejection fraction. Another factor that may also explain the inverse relation between TRIMPS and HRV indices is the potential for adrenal exhaustion associated with 21 day stage races. Previous work from Lucia et $a l^{6}$ during the 1999 Vuelta a España has shown a decrease in basal concentrations of several hormones associated with the basal activity of the pineal gland, adrenal glands, and testis, suggesting a degree of adrenal exhaustion in professional riders during this type of activity.

Our study has several limitations because of its nature as a field study. Firstly, we did not have a control group with which to compare our data. This may be partially overcome through our analysis, which accounted for each rider's relative degree of exercise volume and intensity. Secondly, we were not able to control for breathing during this trial, as this was performed under professional racing conditions and "extracurricular" rider time was at a premium. Previous research has shown that uncontrolled breathing may cause a shift of the respiratory peak, as assessed by frequency domain analysis, from high frequency to the lower frequencies and result in an increase in low frequency power $\left(\mathrm{P}_{\mathrm{LF}}\right)$ and a decrease in high frequency power $\left(\mathrm{P}_{\mathrm{HF}}\right) .{ }^{27}$ However, riders were compared against themselves under consistent resting conditions and showed no decrease in high frequency power, 


\section{Take home message}

Overtraining and overreaching are not clearly understood or easily monitored. The use of HRV shows promise in diagnosing these maladies, but may be confounded if group mean responses that do not account for individual differences are examined. The TRIMP concept offers a solution to this problem that is simple to administer by accounting for the individual exertion response of each athlete to a training stimulus.

which has been shown not to influence HRV outcomes appreciably. ${ }^{41}$ Lastly, it should be mentioned that alterations in HRV are influenced by simultaneous training induced changes that are also non-linear. ${ }^{42}{ }^{43}$ Thus, the best way to study true autonomic balance would be by the use of drugs to block the sympathetic and/or the parasympathetic system, as HRV only gives an indirect estimation of autonomic balance. However, this approach would be impractical in day to day monitoring of training athletes.

Our data strongly suggest that changes in HRV are directly related to volume and intensity of exercise, as athletes who showed the greatest cumulative physical exertion also showed the largest decrease in supine HRV. We therefore suggest that future investigations of the relation between long periods of chronic physical exertion should devise means of quantifying the intensity/volume relation of the athletes under investigation. Given the extent and ease of use of HR monitors today, this can be easily accomplished for most endurance athletes using this type of HR monitoring technology.

\section{Authors' affiliations}

C P Earnest, R Jurca, T S Church, The Cooper Institute Center for Human Performance and Nutrition Research, Dallas, Texas, USA

J L Chicharro, Universidad Complutense de Madrid, Spain

J Hoyos, Agrupación Deportiva Banesto

A Lucia, Universidad Europea de Madrid, Spain

\section{REFERENCES}

1 Hooper SL, Mackinnon LT, Howard A, et al. Markers for monitoring overtraining and recovery. Med Sci Sports Exerc 1995;27:106-12.

2 Douglas PS, O'Toole ML. Cardiovascular and hematologic alterations. In: Kreider RB, Fry AC, O'Toole ML, eds. Overtraining in sport. Champaign, IL: Human Kinetics, 1998:403.

3 Kuipers H, Keizer HA. Overtraining in elite athletes. Review and directions for the future. Sports Med 1988;6:79-92.

4 Lentini AC, McKelvie RS, McCartney $\mathrm{N}$, et al. Left ventricular response in healthy young men during heavy-intensity weight-lifting exercise. J Appl Physiol 1993;75:2703-10.

5 Lehmann M, Foster C, Keul J. Overtraining in endurance athletes: a brief review. Med Sci Sports Exerc 1993;25:854-62.

6 Lucia A, Diaz B, Hoyos J, et al. Hormone levels of world class cyclists during the Tour of Spain stage race. Br J Sports Med 2001;35:424-30.

7 Bonaduce D, Petretta M, Cavallaro V, et al. Intensive training and cardiac autonomic control in high level athletes. Med Sci Sports Exerc 1998; $30: 691-6$

8 Hedelin R, Wiklund U, Bierle $P$, et al. Pre- and post-season heart rate variability in adolescent cross-country skiers. Scand J Med Sci Sports 2000; 10:298-303.

9 Hedelin R, Wiklund $U$, Bierle $P$, et al. Cardiac autonomic imbalance in an overtrained athlete. Med Sci Sports Exerc 2000;32:1531-3.

10 Uusitalo AL, Laitinen T, Vaisanen SB, et al. Effects of endurance training on heart rate and blood pressure variability. Clin Physiol Funct Imaging 2002;22:173-9

11 Uusitalo AL, Uusitalo AJ, Rusko HK. Exhaustive endurance training for 69 weeks did not induce changes in intrinsic heart rate and cardiac autonomic modulation in female athletes. Int J Sports Med 1998;19:532-40.

12 Uusitalo AL, Uusitalo AJ, Rusko HK. Heart rate and blood pressure variability during heavy training and overtraining in the female athlete. Int J Sports Med 2000;21:45-53.
13 Pichot V, Roche F, Gaspoz JM, et al. Relation between heart rate variability and training load in middle-distance runners. Med Sci Sports Exerc 2000;32:1729-36.

14 Portier H, Louisy F, Laude $D$, et al. Intense endurance training on heart rate and blood pressure variability in runners. Med Sci Sports Exerc 2001;33:1120-5.

15 Uusitalo AL, Tahvanainen KU, Uusitalo AJ, et al. Non-invasive evaluation of sympathovagal balance in athletes by time and frequency domain analyses of heart rate and blood pressure variability. Clin Physiol 1996;16:575-88.

16 Pichot V, Busso T, Roche F, et al. Autonomic adaptations to intensive and overload training periods: a laboratory study. Med Sci Sports Exerc 2002:34:1660-6.

17 Nolan J, Batin PD, Andrews R, et al. Prospective study of heart rate variability and mortality in chronic heart failure: results of the United Kingdom heart failure evaluation and assessment of risk trial (UK-heart). Circulation 1998:98:1510-16.

18 Galinier M, Pathak A, Fourcade J, et al. Depressed low frequency power of heart rate variability as an independent predictor of sudden death in chronic heart failure. Eur Heart J 2000;21:475-82.

19 Banister EW, Calvert TW. Planning for future performance: implications for long term training. Can J Appl Sport Sci 1980;5:170-6.

20 Foster C, Florhaug JA, Franklin J, et al. A new approach to monitoring exercise training. J Strength Cond Res 2001;15:109-15.

21 Lucia A, Carvajal A, Calderon FJ, et al. Breathing pattern in highly competitive cyclists during incremental exercise. Eur J Appl Physiol Occup Physiol 1999;79:512-21

22 Garcia-Roves PM, Terrados N, Fernandez SF, et al. Macronutrient intake of top level cyclists during continuous competition: change in the feeding pattern. Int J Sports Med 1998;19:61-7.

23 Lucia A, Hoyos J, Perez M, et al. Heart rate and performance parameters in elite cyclists: a longitudinal study. Med Sci Sports Exerc 2000;32:1777-82.

24 Huikuri HV, Linnaluoto MK, Seppanen T, et al. Circadian rhythm of heart rate variability in survivors of cardiac arrest. Am J Cardiol 1992;70:610-15.

25 Huikuri HV, Seppanen T, Koistinen MJ, et al. Abnormalities in beat-to-beat dynamics of heart rate before the spontaneous onset of life-threatening ventricular tachyarrhythmias in patients with prior myocardial infarction. Circulation 1996;93:1836-44.

26 Melanson EL. Resting heart rate variability in men varying in habitual physical activity. Med Sci Sports Exerc 2000;32:1894-901.

27 Task Force of the European Society of Cardiology and the North American Society of Pacing and Electrophysiology. Heart rate variability: standards of measurement, physiological interpretation and clinical use. Circulation 1996;93:1043-65

28 Uusitalo AL, Uusitalo AJ, Rusko HK. Endurance training, overtraining and baroreflex sensitivity in female athletes. Clin Physiol 1998; 18:510-20.

29 Hedelin R, Kentta G, Wiklund U, et al. Short-term overtraining: effects on performance, circulatory responses, and heart rate variability. Med Sci Sports Exerc 2000:32:1480-4.

30 Kenney WL. Parasympathetic control of resting heart rate: relationship to aerobic power. Med Sci Sports Exerc 1985;17:451-5.

31 Smith ML, Hudson DL, Graitzer HM, et al. Exercise training bradycardia: the role of autonomic balance. Med Sci Sports Exerc 1989;21:40-4.

32 Schaefer ME, Allert JA, Adams HR, et al. Adrenergic responsiveness and intrinsic sinoatrial automaticity of exercise-trained rats. Med Sci Sports Exerc 1992;24:887-94.

33 Katona PG, McLean M, Dighton DH, et al. Sympathetic and parasympathetic cardiac control in athletes and nonathletes at rest. J Appl Physiol 1982;52:1652-7

34 Lehmann $\mathrm{M}$, Foster $\mathrm{C}$, Dickhuth $\mathrm{HH}$, et al. Autonomic imbalance hypothesis and overtraining syndrome. Med Sci Sports Exerc 1998;30:1140-5.

35 Eysmann SB, Gervino E, Vatner DE, et al. Prolonged exercise alters betaadrenergic responsiveness in healthy sedentary humans. J Appl Physiol 1996:80:616-22.

36 Chen SA, Yang CJ, Chiang CE, et al. Reversibility of left ventricular dysfunction after successful catheter ablation of supraventricular reentrant tachycardia. Am Heart J 1992;124:1512-6

37 Packer DL, Bardy GH, Worley SJ, et al. Tachycardia-induced cardiomyopathy: a reversible form of left ventricular dysfunction. Am J Cardiol 1986;57:563-70.

38 Shannon RP, Komamura K, Stambler BS, et al. Alterations in myocardial contractility in conscious dogs with dilated cardiomyopathy. Am J Physiol 1991;260:H1903-11.

39 Friedman DB, Ordway GA, Williams RS. Exercise-induced functional desensitization of canine cardiac beta-adrenergic receptors. J Appl Physiol 1987;62:1721-3.

40 Rifai N, Douglas PS, O'Toole M, et al. Cardiac troponin T and I, echocardiographic [correction of electrocardiographic] wall motion analyses, and ejection fractions in athletes participating in the Hawaii Ironman Triathlon. Am J Cardiol 1999:83:1085-9.

41 Patwardhan A, Evans J, Bruce E, et al. Heart rate variability during sympathoexcitatory challenges: comparison between spontaneous and metronomic breathing. Integr Physiol Behav Sci 2001;36:109-20.

42 Melanson EL, Freedson PS. The effect of endurance training on resting heart rate variability in sedentary adult males. Eur J Appl Physiol 2001;85:442-9.

43 Zaza A, Lombardi F. Autonomic indexes based on the analysis of heart rate variability: a view from the sinus node. Cardiovasc Res 2001;50:434-42. 